\title{
A study of knowledge, attitude and practices regarding hair dye use among general population
}

\section{Mrinal Gupta}

\author{
Department of Dermatology, Treatwell Skin Centre, Jammu and Kashmir, India
}

Corresponding author: Dr. Mrinal Gupta, E-mail: drmrinalgupta@yahoo.com

\begin{abstract}
Background: Hair dye usage is extremely common all over the world. Hair dyes have been reported to cause a wide range of adverse effects, therefore, the consumer's knowledge about hair dyeing and related side effects are important. Aim: To assess the knowledge, attitude and practices of general population towards the use of hair dyes. Materials and Methods: Two hundred and fifty consecutive persons using hair dyes were enrolled for this questionnaire-based cross-sectional, descriptive study. Results: These 250 patients comprised 141 men (56.4\%) and 109 women (43.6\%) (M: F 1.29:1), aged between 16 and 74 (mean 47.13) years. The majority, 212 patients (84.8\%) were aged between 20-60 years and 66.4\% ( $\mathrm{n}=166)$ belonged to an urban background. When asked about the reason for using hair color, the principle reason was "to look younger" $(59.6 \%, \mathrm{n}=149)$. Most of the respondents were using synthetic hair dye preparations $(55.2 \%, \mathrm{n}=138)$ and when asked about the brand of hair dye being used, $25.2 \%(\mathrm{n}=63)$ did not know about the brand they were using. When asked about their perception regarding safety of HD, $61 \%(n=152)$ respondents agreed that hair dyes are not safe and on being asked about the carcinogenic potential of HD, only $24 \%$ $(n=60)$ respondents agreed. When enquired about the safest variety of HD, majority of respondents $(52.4 \%, n=131)$ believed that plant based hair colors are the safest. When asked about the safety of HD during pregnancy and lactation, $68 \%(n=168)$ of the respondents were unaware regarding this aspect. $14.4 \%$ of the respondents reported suffering from some adverse effects due to hair dye use but only $11.11 \%(n=4)$ of those stopped using hair dyes. Conclusions: There is lack of awareness about the hair dyes and their adverse effects in the general population. There is an urgent need to increase awareness among consumers regarding the adverse effects of hair dyes and the available safer alternatives. Limitations: Small number of respondents and the use of a convenience sample, which might not be representative of the whole community.
\end{abstract}

Key words: Hair dye; PPD; Cosmetic dermatitis; Contact dermatitis; Hair colors; PPD sensitization

\section{INTRODUCTION}

Hair dyes (HD) are perhaps among the most commonly used cosmetics by elderly and the young alike - for concealing gray hair by the former or just for a fashion statement by the latter. The popularity of hair coloring can be gauged from the fact that the median age for debut was 16 years and nearly $75 \%$ of women and $18 \%$ of men had dyed their hair at some point in their lives according to a Danish population-based study [1]. This rising trend of hair coloring has resulted in an increased prevalence of hair dye-associated adverse effects, which vary from mild contact dermatitis localized to one body site (hand dermatitis) or disseminated generalized dermatitis to severe life threatening complications such as contact urticaria/angioedema, rhinitis/bronchospasm/asthma, and renal toxicity $[2,3]$.

Adequate knowledge and accurate information about hair dye usage and its adverse effects are important for the general population. Identification of correlates of poor knowledge, casual attitude, and wrong perceptions among the hair dye users will help in reducing the prevalence of hair dye associated complications. However, there is a paucity of literature on the level of knowledge, attitude, and perceptions of general

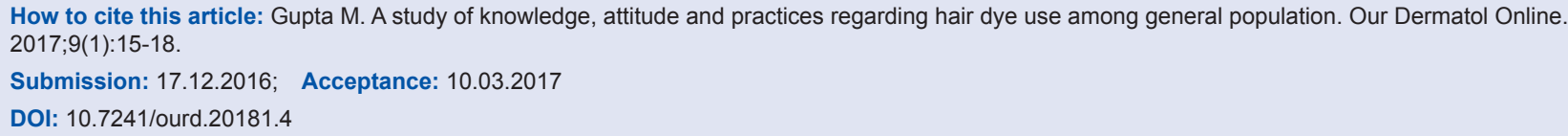


population toward hair dye usage. This study assesses the knowledge, attitude, and perceptions of general population towards hair dyes attending a dermatology outpatient clinic.

\section{MATERIALS AND METHODS}

All patients using hair dyes, attending outpatient dermatology clinic during October 2015 to September 2016 were enrolled for this questionnaire based, cross-sectional, descriptive study. Children aged $<14$ years and severely ill patients were excluded from the study owing to their inability to comprehend or respond to the questionnaire. After informed written consent and assuring confidentiality, they were asked to answer a predesigned, structured questionnaire in their native language. The questionnaire had two parts with the first section for their sociodemographic details and the second section comprised questions aimed at assessing their knowledge, attitude, and perception towards hair dyes.

\section{RESULTS}

These 250 patients comprised 141 men (56.4\%) and 109 women (43.6\%) (M: F 1.29:1), aged between 16 and 74 (mean 47.13 ) years. Their baseline demographic features are shown in Table 1. The majority, 212 patients (84.8\%) were aged between 20-60 years and 66.4\% $(n=166)$ of the study group belonged to an urban background. Most subjects $(48.4 \%, \mathrm{n}=121)$ started coloring their hair after 40 years of age, with the median age being 43.7 years (Table 2). When asked about

\begin{tabular}{lc} 
Table 1: Baseline characteristics of the study population \\
\hline Baseline characteristics of the & $\begin{array}{c}\text { Total number of } \\
\text { patients }(\mathbf{n}=250)\end{array}$ \\
patients studied & $141: 109$ \\
\hline Gender (male: female) & \\
Age (years) & $16-74(47.13)$ \\
Range (mean) & $14(5.6 \%)$ \\
$<20$ yrs & $84(33.6 \%)$ \\
$20-39$ yrs & $128(51.2 \%)$ \\
$40-59$ yrs & $24(9.6 \%)$ \\
$>60$ yrs & \\
Social background & $166(66.4 \%)$ \\
Urban & $84(33.6 \%)$ \\
Rural & \\
Duration of hair dye use & 28 years $(7.43$ years) \\
Range (mean) & \\
Frequency of hair dye use & $56(22.4 \%)$ \\
Once a year & $74(29.6 \%)$ \\
$2-6$ times/year & $120(48 \%)$ \\
$>6$ times/year & $149(59.6 \%)$ \\
Reason for using hair dye & $51(20.4 \%)$ \\
To appear younger & $27(10.8 \%)$ \\
As a fashion statement & $23(9.2 \%)$ \\
Recommended by others & \\
Others &
\end{tabular}

the reason for using hair color, the principle reasons were "to look younger" $(59.6 \%, \mathrm{n}=149)$, "as a fashion statement" $(20.4 \%, \mathrm{n}=51)$ and "recommendation by others" $(10.8 \%, n=27)$. On the brand of hair dye being used, a sizeable minority $(25.2 \%, \mathrm{n}=63)$ did not know about the brand they were using. Most of the respondents were using synthetic hair dye preparations $(55.2 \%, \mathrm{n}=138)$ but a large proportion of the study group reported using herbal/plant based hair coloring products $(44.8 \%, \mathrm{n}=112)$. When questioned on the frequency of HD use, $48 \%(n=120)$ indicated that they did so more than 6 times in a year and when asked about the interval between two consecutive HD applications, their answers ranged from 15 days to 24 months (mean - 3.73 months).

Analysis of the questionnaire (Table 2) revealed that $61 \%(n=152)$ respondents agree that hair dyes are not safe. On being asked about the carcinogenic potential of HD, only $24 \%(n=60)$ respondents agreed. When enquired about the safest variety of HD, majority of respondents $(52.4 \%, \mathrm{n}=131)$ believed that plant based hair colors are the safest. When asked about the safety of HD during pregnancy and lactation, 67\% ( $n=168)$ of the respondents were unaware regarding this aspect. When the participants were asked if they performed an allergy test before using a new $\mathrm{HD}$, only $6 \%(n=15)$ reported that they did so before using a new hair coloring product and only $29 \%(n=73)$ respondents said that they read the application instructions before applying the product. When enquired about the adverse effects, 36 respondents (14.4\%) reported adverse effects with the use of HD. The most common adverse effect was itching, followed by erythema and swelling. From the 36 respondents who experienced side effects, only $12(33.3 \%)$ visited a medical provider for treatment. When enquired regarding the reasons for not visiting a medical provider, $19(52.77 \%)$ answered that the adverse effects were not severe, while the others considered them as part of hair dyeing $(11.1 \%$, $n=4)$ or did some self-medication for the same $(2.77 \%$, $\mathrm{n}=1)$. Despite the adverse effects, only 4 patients (11.1\%) stopped using hair dyes, 7 (19.44\%) changed the product while the remainder persisted with the same hair coloring agent.

\section{DISCUSSION}

The use of hair colorants has increased exponentially over the last few decades due to increased societal pressure and changing fashion trends. Over the years, 
www.odermatol.com

Table 2 :Results of questionnaire on hair dye related knowledge, attitude, and perception

\begin{tabular}{|c|c|c|c|}
\hline \multirow[t]{2}{*}{ Questions } & \multicolumn{3}{|c|}{$\mathrm{n}=\mathbf{1 5 0}(\%)$} \\
\hline & Yes & No & No answer/don't know \\
\hline 1. Are the hair dyes safe? & $35(14)$ & $152(60.8)$ & $63(25.2)$ \\
\hline 2. Can hair dyes cause cancer? & $60(24)$ & $48(19.2)$ & $142(56.8)$ \\
\hline 3. Can hair dyes be used during pregnancy and lactation? & $31(12.4)$ & $51(20.4)$ & $168(67.2)$ \\
\hline \multicolumn{4}{|l|}{ 4. Which are the safest type of hair dyes } \\
\hline - Synthetic & $44(17.6)$ & & \\
\hline -Plant based/herbal & $131(52.4)$ & & \\
\hline - Don’t know & $75(30)$ & & \\
\hline 5. Do you perform allergy testing before using hair dye? & $15(6)$ & $149(59.6)$ & $86(34.4)$ \\
\hline 6. Do you read the instruction manual before using hair dye? & $73(29.2)$ & $109(43.6)$ & $68(27.2)$ \\
\hline 7. Have you ever experienced any adverse effect with hair dye use? & $36(14.4)$ & $187(74.8)$ & $27(10.8)$ \\
\hline a. If yes, did you consult a medical practitioner for the same? & $12 / 36(33.3)$ & $22 / 36(61.11)$ & $2(5.55)$ \\
\hline 8. Are you still using hair dye even after experiencing side effects? & $31 / 36(86.11)$ & $4 / 36(11.11)$ & $1 / 36(2.77)$ \\
\hline
\end{tabular}

the coloring agents have diversified in nature with the arrival of oxidative hair dyes that include many synthetic and natural agents. This rising trend of hair coloring has resulted in an increased prevalence of hair dye associated adverse effects [4]. The safety of hair dyes is being under continuous surveillance for the last many years. Hair dyes include a variety of coloring agents such as 2,7-naphthalenediol, 2 - aminomethyl-p aminophenol hydrochloride, 2-chloro-p-phenylenediamine and p-phenylenediamine which have been implicated in the etiology of various disorders [5]. Numerous researchers have reported life threatening adverse effects like renal toxicity and angioedema with their use apart from allergic contact dermatitis, whereas, a few studies have also linked hair dye use with the development of certain malignancies. The most common cutaneous adverse effects include contact dermatitis localized to sites of contact or photoexposed skin, periorbital dermatitis, airborne contact dermatitis, hand dermatitis and disseminated eczema [6]. Keeping in view, the numerous health hazards associated with the use of HD, it becomes important that the general population should be well aware of the various aspects of HD usage and their associated adverse effects. Therefore, we tried to assess the public's knowledge, attitudes, and practices towards HD.

In today's world, the desire to look younger is widespread which is being reinforced everyday by the media and the social media. Many people do not want graying hair and they seek hair dyeing products to cover it. This is supported by our survey responses that most respondents said they color their hair to look younger. The prevalence of HD usage can be gauged from the fact that more than $50 \%$ of women in the industrial world use HDs [7]. The median age of starting hair dye use is also becoming younger with the median age at first hair dyeing being 16 years in a Danish study, 22 years in a study from middle-east, and 27 years in an Indian study but in our study group, the median age was 38.7 years indicating that HD use is not extremely high among teenagers and young adults in our society $[1,8,9]$. A large number of respondents in our study did not know the hair color brand which they were using, and majority was unaware of the allergy testing before application and the application instructions. In a study by Kim et al, 73\% of the respondents were unaware of the hair color brand they were using [10].

A large proportion of population in our study group believed that hair dyes are harmful, while in a study by Al Ghamdi et al, 52\% respondents were aware of the harms of hair dyes [8]. In our study, 36 respondents (14.4\%) reported adverse effects with the use of hair dyes which is higher than the prevalence rate of $5.2 \%$ in a Danish study but lesser than the $42 \%$ prevalence rate reported in an Indian study $[1,10]$. Despite the experience of side effects, most of the people (32 out of 36) continued hair dyeing. Furthermore, only a small portion of the respondents (12 out of 36) who experienced side effects visited a medical practitioner for treatment as the others considered the adverse effects to be minor or considered them as a part of hair dyeing.

There are very few studies concerning HD use during human pregnancy [11]. Animal studies have shown that doses 100 times higher than the dose normally used in human application did not produce significant changes in fetal development. But low levels of HD can be absorbed through the skin after application, which does not cause a developmental problem to the fetus $[12,13]$. However, the use of HDs during pregnancy is not recommended and might be associated with future health problems in children [14]. The lack of knowledge regarding the adverse effects of HD and their safety profile during pregnancy and lactation in a majority of respondents in our study indicates the lack of knowledge and awareness regarding HD in our population. 


\section{Limitations}

Our study had certain limitations also. The small number of respondents and the use of a convenience sample might not be representative of the whole community.

\section{CONCLUSIONS}

There is lack of awareness about the hair dyes and their adverse effects in the general population. There is an urgent need to increase awareness among consumers regarding the adverse effects of hair dyes, the available safer alternatives, and the significance of performing sensitivity testing prior to actual use, in adherence of usage instructions. It is also desirable that manufacturers print directions in bold text over the product package regarding safe use of the hair dye.

\section{REFERENCES}

1. Søsted H, Hesse U, Menné T, Andersen KE, Johansen JD, Sosted $\mathrm{H}$, et al. Contact dermatitis to hair dyes in an adult Danish population-An interview-based study. Br J Dermatol. 2005;153:132-5.

2. Helaskoski E, Suojalehto H, Virtanen H, Airaksinen L, Kuuliala O, Aalto-Korte K, et al. Occupational asthma, rhinitis, and contact urticaria caused by oxidative hair dyes in hairdressers. Ann Allergy Asthma Immunol. 2014;112:46-52.

3. Fukunaga T, Kawagoe R, Hozumi H, Kanzaki T. Contact anaphylaxis due to para-phenylenediamine. Contact Dermatitis. 1996;35:185-6.

4. Uter W, Lessmann H, Geier J, Schnuch A. Contact allergy to ingredients of hair cosmetics in female hairdressers and clients-an 8-year analysis of IVDK data. Contact Dermatitis. 2003;49:236-40.

5. Sosted H, Basketter DA, Estrada E, Johansen JD, Patlewicz GY. Ranking of hair dye substances according to predicted sensitization potency-quantitative structure-activity relationships. Contact Dermatitis. 2004;51:241-54.

6. Gupta M, Mahajan VK, Mehta KS, Chauhan PS. Hair dye dermatitis and p-phenylenediamine contact sensitivity: A preliminary report. Indian Dermatol Online J. 2015;6:241-5.

7. Søsted H, Rastogi SC, Andersen KE, Johansen JD, Menné T. Hair dye contact allergy: Quantitative exposure assessment of selected products and clinical cases. Contact Dermatitis. 2004;50:344-8.

8. AlGhamdi KM, Moussa NA. Knowledge and practices of, and attitudes towards, the use of hair dyes among females visiting a teaching hospital in Riyadh, Saudi Arabia. Ann Saudi Med. 2011;31:613-9.

9. Patel D, Narayana S, Krishnaswamy B. Trends in use of hair dye: A cross-sectional study. Int J Trichol. 2013;5:140-3.

10. Kim JE, Jung HD, Kang H. A Survey of the Awareness, Knowledge and Behavior of Hair Dye Use in a Korean Population with Gray Hair. Ann Dermatol. 2012;24:274-9.

11. Blackmore-Prince C, Harlow SD, Gargiullo P, Lee MA, Savitz DA. Chemical hair treatments and adverse pregnancy outcome among Black women in central North Carolina. Am J Epidemiol. 1999;149:712-6.

12. DiNardo JC, Picciano JC, Schnetzinger RW, Morris WE, Wolf BA, et al. Teratological assessment of five oxidative hair dyes in the rat. Toxicol Appl Pharmacol. 1985;78:163-6.

13. Burnett C, Goldenthal EI, Harris SB, Wazeter FX, Strausburg J, Kapp R, et al. Teratology and percutaneous toxicity studies on hair dyes. J Toxicol Environ Health. 1976;1:1027-40.

14. McCall EE, Olshan AF, Daniels JL. Maternal hair dye use and risk of neuroblastoma in offspring. Cancer Causes Control. 2005;16:743-8.

Copyright by Mrinal Gupta. This is an open-access article distributed under the terms of the Creative Commons Attribution License, which permits unrestricted use, distribution, and reproduction in any medium, provided the original author and source are credited.

Source of Support: Nil, Conflict of Interest: None declared. 